\title{
Recovery of Boron from Underground Brine by Continuous Centrifugal Extraction with 2-Ethyl-1,3-hexanediol (EHD) and Its Mechanism
}

\author{
Xuebing Fan, Xiaoping Yu $(D$, Yafei Guo $\mathbb{D}$, and Tianlong Deng $(\mathbb{D}$ \\ Tianjin Key Laboratory of Marine Resources and Chemistry, College of Chemical Engineering and Materials Science, \\ Tianjin University of Science and Technology, Tianjin 300457, China \\ Correspondence should be addressed to Xiaoping Yu; yuxiaoping@tust.edu.cn and Tianlong Deng; tldeng@tust.edu.cn
}

Received 1 May 2018; Accepted 29 August 2018; Published 9 October 2018

Academic Editor: Carlos A. Martínez-Huitle

Copyright (c) 2018 Xuebing Fan et al. This is an open access article distributed under the Creative Commons Attribution License, which permits unrestricted use, distribution, and reproduction in any medium, provided the original work is properly cited.

In order to economical and environmental-friendly recycle of boron from underground brine, the extraction of boron was carried out in this work by the continuous centrifugal technique using 2-ethyl-1,3-hexanediol (EHD) + sulfonated kerosene (SK) extraction system, and the extraction mechanism was also investigated by the combination of FT-IR with slope method. The results showed that boron can be effectively extracted from underground water with the concentration of boron $5.43 \mathrm{~g} \cdot \mathrm{L}^{-1}$ by five-stage centrifugal extraction using $30 \% \mathrm{EHD}+70 \% \mathrm{SK}$ at $\mathrm{pH}=2.0-3.0, R(\mathrm{O} / \mathrm{A})=1: 2$, and the extraction rate reached $98.46 \%$. Boron in the organic phase can be well five-stage back-extracted by $1.0 \mathrm{~mol} \cdot \mathrm{L}^{-1} \cdot \mathrm{NaOH}$ at $R(\mathrm{O} / \mathrm{A})=1: 1$ with a back-extraction rate of $97.00 \%$. About $88.32 \%$ boron in the aqueous phase obtained by back-extraction can be recycled in $\mathrm{H}_{3} \mathrm{BO}_{3}$ form by evaporation crystallization after acidified to $\mathrm{pH}<2.5$. The extraction mechanism indicated that the extraction is completed mainly based on the esterification reaction between alcoholic hydroxyl in $\mathrm{EHD}$ and $-\mathrm{OH}$ in $\mathrm{B}(\mathrm{OH})_{3}$ at the stoichiometric ratio $1: 1$ to generate a stable six-membered ring structure of boric acid ester.

\section{Introduction}

Boron and its compounds are widely applied in modern industry due to their excellent characteristics such as heat and wear resistance, high strength, and rigidity [1]. Boron mainly exists in solid boron ores and liquid ores in the form of boric or borate salts [2], but after several decades of exploitation, the solid boron resources have become increasingly exhausted. It is well known that there are plentiful of brine resources containing abundant boron all over the world, including salt lake brine, underground brine, oil-field brine, and so on. However, resulting from the interference of high concentration of coexisting ions such as $\mathrm{Na}^{+}, \mathrm{K}^{+}, \mathrm{Mg}^{2+}$, and $\mathrm{Cl}^{-}$in brine, the industrial production of boron from brine has not yet been well carried out [3]. Therefore, the development of a swift and low-cost method for the separation and extraction of boron from brine will be of great significance and will bring about considerable economic benefits [4].
At present, many separation techniques have already been reported to separate boron from brine, such as adsorption [5], chemical precipitation [6], reverse osmosis [7], solvent extraction [8,9], and so on. Wherein, solvent extraction is one of the nonenergy intensive mass transfer processes and is widely used to separate and recycle valuable elements from complex matrix for its high selectivity and recovery. Various extractants have been developed to extract boron from brine, especially based on the extraction system containing alcohol, such as monohydric alcohols, dibasic alcohols, and mixed alcohols. For example, $n$-hexanol, $n$-octanol, isooctyl alcohol, $n$-decanol, and other fatty alcohols were used by Hejda and Jedináková $[10,11]$ to extract boron from radioactive waste water, and the results indicated that isooctanol had the best effect. 2,2,5-Trimethyl-1,3-hexanediol was used by Karakaplan et al. [12] to extract boron from aqueous solution, and the extraction rate reached to $96.8 \%$ at the optimizing conditions. Kwon et al. [13] studied the extraction 
equilibrium during boron extraction and stripping with 2-butyl-2-ethyl-1,3-propanediol, and the result shows that boron extraction was intensive in acidic solution, while the stripping took place dominantly in the alkaline solution. Usually, dibasic alcohols have higher extraction ability when compared with monohydric alcohols due to the generation of more stable extracted complexes.

The conventional solvent extraction equipment used in industrial production is the mixer-settler, by which the extraction and separation are achieved mainly based on the density difference of two immiscible phases $[14,15]$. It is noted that if the aqueous phase and organic phase have little density differences, the gravity-based settling will be impracticability. However, this problem can be effectively solved by the introduction of the centrifugal extraction technique, by which it can significantly enhance the extraction efficiency and velocity. For example, both Gao et al. [16] and Guo [17] extracted boron from brine by the centrifugal extractor, and the results revealed the feasibility of boron extraction from brine by the centrifugal extraction technique.

Although dibasic alcohols present excellent properties for boron extraction from brine, few studies were carried out based on the centrifugal extraction technique. As the retention time of aqueous phase and organic phase (or the contact time between aqueous phase and organic phase) in the extractor is shorter when compared with the mixer-settler, many factors need to be investigated including extraction stage, extraction and back-extraction effects, and so on. In this paper, 2-ethyl-1,3-hexanediol was chosen as the extractant to extract boron from underground brine. The extraction and back-extraction were carried out on a continuous centrifugal extractor, and the extraction conditions and mechanism were investigated systematically based on relevant chemical and instrumental analysis.

\section{Experimental}

2.1. Apparatus. The extraction operation was carried out using a five-stage continuous centrifugal extractor (50 model, Tianyi extraction, China). The concentrations of metal ions were determined by an inductively coupled plasma optical emission spectrometer (ICP-OES, Prodigy XP ICP, Leman Corporation, USA). The acidity of brine was determined by an acidometer (PHSJ-5, Leici, China). The density of brine was measured by a densimeter (DMA 4500M, Anton Paar, Austria). The viscosities of organic phase and aqueous phase were determined by an Ubbelohde viscometer.

2.2. Materials and Reagents. The underground brine collected from Dazhou in China was concentrated to increase the concentration of boron prior to the extraction. The compositions of brine after sevenfold concentration are shown in Table 1, and its density and viscosity at room temperature $(298.15 \mathrm{~K})$ were determined to be $1.2967 \mathrm{~g} \cdot \mathrm{mL}^{-1}$ and $1.86 \cdot \mathrm{mPa} \cdot \mathrm{s}$, respectively.
The extractant 2-ethyl-1,3-hexanediol (EHD; $\rho=0.9405 \mathrm{~g} \cdot \mathrm{mL}^{-1}$ and $\mu=323.06 \mathrm{mPa} \cdot \mathrm{s}$ ) was supplied by the Tianjin Heowns Bio. Technology Co. Ltd. The diluent sulfonated kerosene (SK; $\rho=0.8205 \mathrm{~g} \cdot \mathrm{mL}^{-1}$ and $\mu=2.25 \mathrm{mPa} \cdot \mathrm{s}$ ) was purchased from the Tianjin Jinweier Chemical Co. Ltd. The other reagents used during the experiment were supplied by the Sinopharm Chemical Reagent Co. Ltd. Doubly deionized water (DDW) with a conductivity less than $1 \times 10^{-4} \mathrm{~S} \cdot \mathrm{m}^{-1}$ and $\mathrm{pH}=6.60$ at room temperature was used throughout the experiment.

2.3. Experimental Methods. The organic phase was prepared using EHD and SK at certain proportion previous to the extraction operation. The brine and organic phase were introduced to the centrifugal extractor from different inlets by two peristaltic pumps, as shown in Figure 1.

When the extraction was equilibrated (about $20 \mathrm{~min}$ ), $5 \mathrm{~mL}$ of raffinate and initial brine was withdrawn to analyze the content of boron by the alkaline titrimetric method with an uncertainty of $\leq \pm 0.3 \%$ in mass [18]. Boron content in the organic phase was calculated by subtraction based on the mass conservation. The other metal ions in the aqueous phase were detected by ICPOES with an uncertainty $\leq \pm 0.5 \%$ in mass [19]. The organic phase was analyzed by Fourier-transform infrared spectrometry (FT-IR, TENSOR-27, Swit Bruker Corporation, Germany) before and after the extraction. The stripping solution was acidized and concentrated to crystallize, and the solid phase was identified by an X-ray diffractometer (X'pert PRO, Spectris. Pte. Ltd., Netherlands). The experimental results were evaluated by extraction rate $(E)$, distribution ratio $(D)$, and backextraction rate (BE). They were defined as

$$
\begin{aligned}
E(\%) & =\frac{m_{\mathrm{O}}}{m_{\mathrm{A}}+m_{\mathrm{O}}} \times 100 \%, \\
D & =\frac{C_{\mathrm{O}}}{C_{\mathrm{A}}} \\
\mathrm{BE}(\%) & =\frac{m_{\mathrm{A}}}{m_{\mathrm{O}}} \times 100 \%,
\end{aligned}
$$

where $m_{\mathrm{A}}$ and $m_{\mathrm{O}}$ are the masses of boron in aqueous phase and organic phase, respectively; $C_{\mathrm{A}}$ and $C_{\mathrm{O}}$ are the molar concentrations of boron in aqueous phase and organic phase, respectively.

\section{Results and Discussion}

\subsection{Extraction of Boron}

3.1.1. Effect of $p H$ and EHD on the Extraction of Boron. The analogous esterification reaction between alcoholic hydroxyl group and boric acid results in the extraction of boron by the organic phase. Therefore, the influences of $\mathrm{pH}$ and EHD on the extraction rate and distribution ratio of boron were investigated by using a single centrifugal extractor at phase ratio $R(\mathrm{O} / \mathrm{A})=1: 2$, and the results are shown in Figure 2. 
TABle 1: Composition of underground brine.

\begin{tabular}{lccccccccc}
\hline Component & $\mathrm{K}^{+}$ & $\mathrm{Na}^{+}$ & $\mathrm{Ca}^{2+}$ & $\mathrm{Mg}^{2+}$ & $\mathrm{Cl}^{-}$ & $\mathrm{SO}_{4}^{2-}$ & $\mathrm{B}_{2} \mathrm{O}_{3}$ & $\mathrm{Br}^{-}$ & $\mathrm{Li}^{+}$ \\
\hline Concentration, g.L L & 55.66 & 63.91 & 3.58 & 22.44 & 225.76 & 2.53 & 17.48 & 3.2 & 0.679 \\
\hline
\end{tabular}

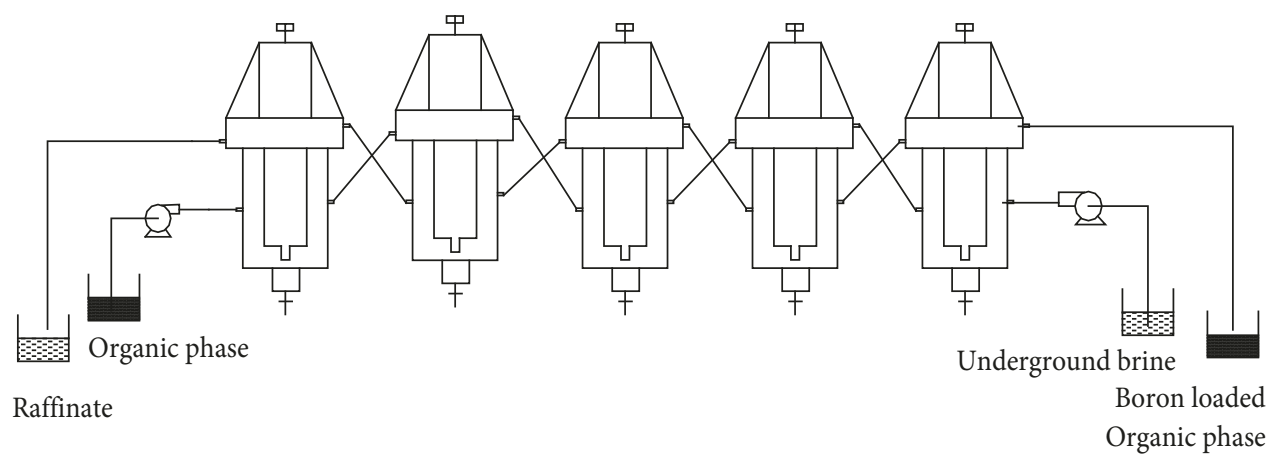

FIGURE 1: Schematic of experimental setup.

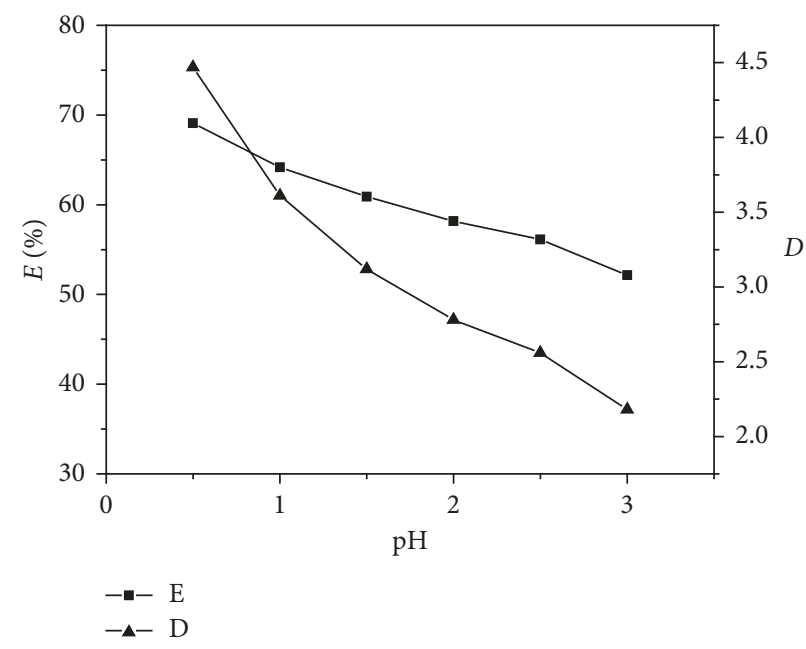

(a)

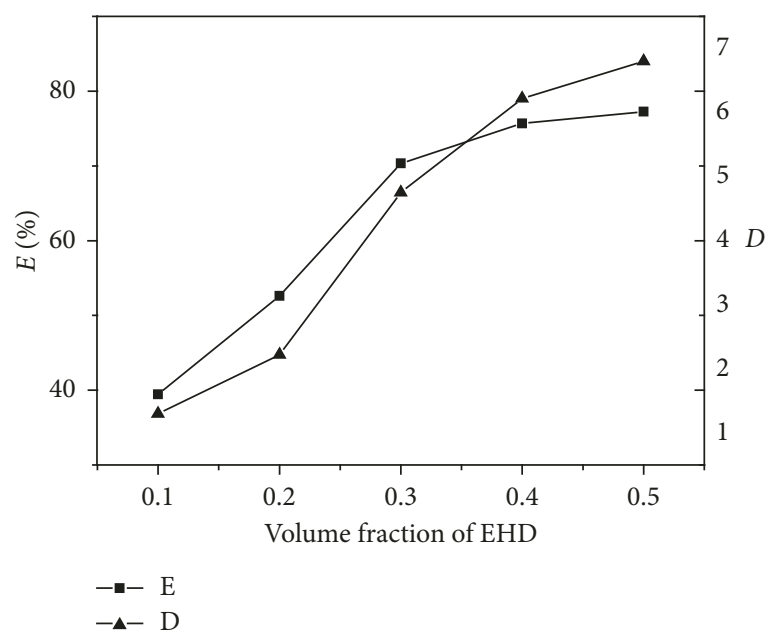

(b)

Figure 2: Effects of brine $\mathrm{pH}$ (a) and EHD (b) on the extraction of boron by single-stage centrifugal extraction at $\mathrm{R}(\mathrm{O} / \mathrm{A})=1: 2$.

Different dissolved boron forms in brine will be transformed into boric acid when brine is acidized to $\mathrm{pH}<2.5$, by which it contributes to the extraction of boron. The extraction rate and distribution ratio of boron decrease with the increase of $\mathrm{pH}$ (Figure 2(a)) as well as the decrease of EHD fraction in the organic phase (Figure 2(b)). With the increase of $\mathrm{pH}$, the amount of boron in brine in the form of associating anions is increased while the amount of boric acid is decreased, resulting in the decrease of effective molecules for esterification so that the extraction rate is decreased. The lower the acidity is, the higher the extraction rate becomes. But in the actual production process, the lower acidity will corrode the extraction equipment and increase the acid consumption. Therefore, $\mathrm{pH}=2$ was selected in this work. When the content of EHD was $30 \%$, the single centrifugal extraction rate reached to $70 \%$, suggesting that both the reaction rate between EHD and boron as well as the mass transfer process between aqueous phase and organic phase were fast. However, when the volume fraction of EHD is larger than 30\%, this variation is not obvious. It is speculated that this result mainly results from the high viscosity of the organic phase (Table 2), by which the mass transfer process between aqueous phase and organic phase is suppressed.

3.1.2. Effect of Phase Ratio $R(O / A)$ and Extraction Stage on the Extraction of Boron. Phase ratio $R(\mathrm{O} / \mathrm{A})$ and extraction stage are the main parameters to influence the extraction of boron by continuous centrifugal extraction; thus, they were 
TABLE 2: Viscosity of organic phase at different EHD fractions (298.15 K).

\begin{tabular}{lcccrr}
\hline EHD (\%) & 10 & 20 & 30 & 40 & 50 \\
\hline Viscosity (mPa.s) & 28.06 & 38.85 & 70.79 & 89.03 & 154.32 \\
\hline
\end{tabular}

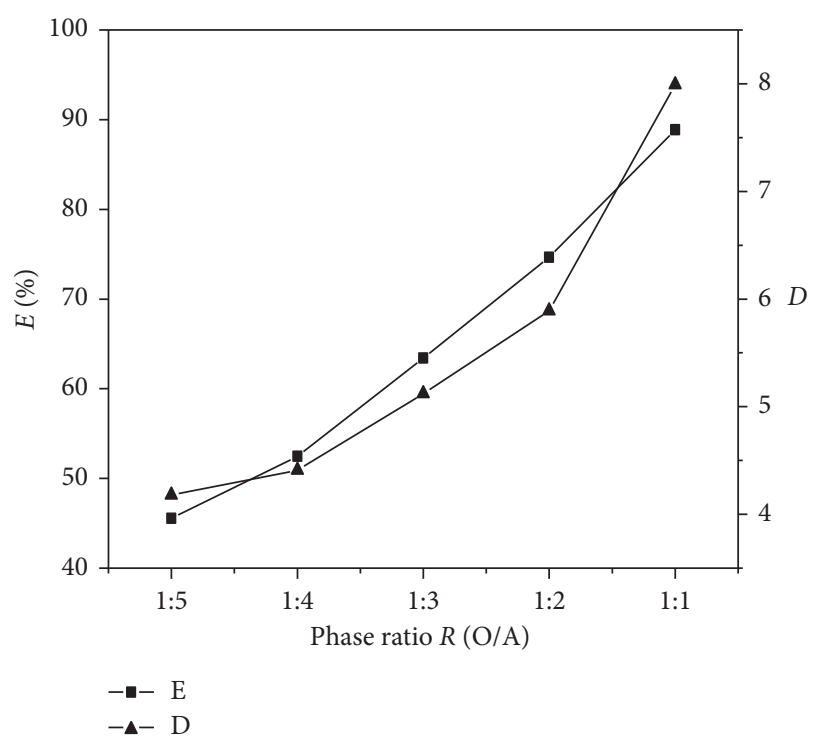

(a)

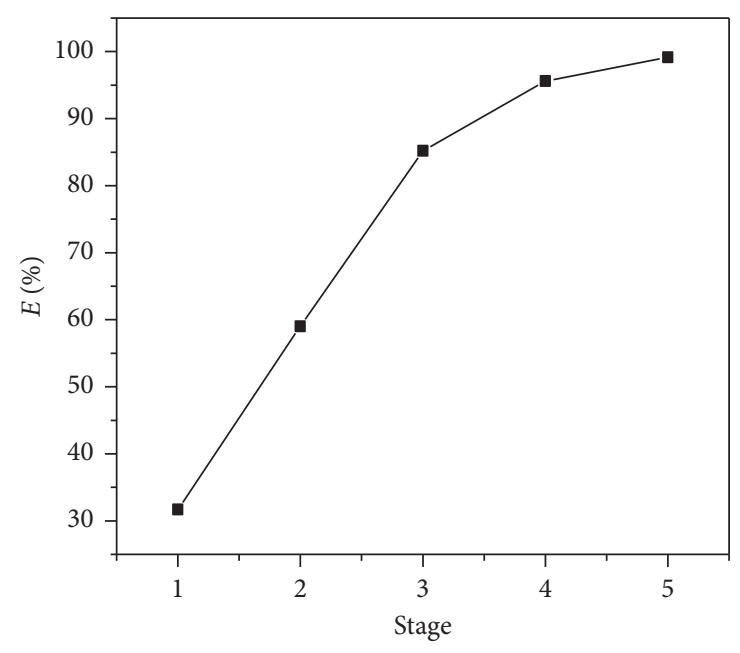

(b)

Figure 3: Effects of phase ratio $\mathrm{R}(\mathrm{O} / \mathrm{A})$ (a) and extraction stage (b) on the extraction of boron by $30 \% \mathrm{EHD}+70 \% \mathrm{SK}$ at $\mathrm{pH}=2.0$.

investigated in detail at the conditions of extraction by $30 \%$ $\mathrm{EHD}+70 \% \mathrm{SK}$ at $\mathrm{pH}=2.0$. The results are shown in Figure 3.

Based on Nernst's distribution law, the higher the $R(\mathrm{O} / \mathrm{A})$ the higher the extraction rate. As it is shown in Figure 3(a) that both extraction rate and distribution ratio of boron increase with the increase of $R(\mathrm{O} / \mathrm{A})$. However, it is noted that the concentration of boron in the organic phase as well as in the aqueous phase after back-extraction will decrease with the increase of $R(\mathrm{O} / \mathrm{A})$. Accordingly, it will sharply increase the energy consumption during the evaporation and concentration of the aqueous phase. Therefore, it is not necessary to blindly pursue a high single extraction rate by increasing the extraction phase ratio. This contradiction between extraction rate and phase ratio can be effectively solved by multistage centrifugal extraction. Based on the results in Figure 3(b), we found that although the single extraction rate is low, it will obviously increase with the extraction stage. After five-stage continuous extraction, a recovery rate of $98.46 \%$ was finally obtained, and the concentration of boron in the organic phase can be concentrated up to $10.79 \mathrm{~g} \cdot \mathrm{L}^{-1}$.

3.2. Back-Extraction of Boron. At present, extensive reports relevant to boron extraction mainly focus on the extraction, and only few involve the back-extraction. Boron is extracted based on the reaction between boric acid and glycol, while the boric acid ester is hydrolyzed during the back-extraction at the action of alkali or acid. After singlestage back-extraction, respectively, by $0.5 \mathrm{~mol} \cdot \mathrm{L}^{-1} \cdot \mathrm{HCl}$ and
$0.5 \mathrm{~mol} \cdot \mathrm{L}^{-1} \mathrm{NaOH}$, we found that the back-extraction rate of $\mathrm{NaOH}(58.3 \%)$ was much higher than that of $\mathrm{HCl}$ (11.6\%). Therefore, both the concentration of $\mathrm{NaOH}$ and phase ratio were further investigated by five-stage centrifugal extraction. The results are shown in Figure 4.

The contact time between aqueous phase and organic phase during the centrifugal back-extraction is quite short; thus, the back-extraction rate of boron is usually low only by single-stage back-extraction. In order to obtain a high recovery of boron, it is necessary to increase the concentration of $\mathrm{NaOH}$ or decrease the phase ratio. Figure 4 shows that the stripping rate increased with the increase of $\mathrm{NaOH}$ concentration as well as the decrease of the phase ratio. Just as it was described above that a low phase ratio will lead to large evaporation quantity of water, it is best to enhance the recovery rate by increasing the concentration of $\mathrm{NaOH}$ or the stage of back-extraction. We found in Figure 4(a) that $97.00 \%$ boron in the organic phase was stripped by five-stage back-extraction using $1.0 \mathrm{~mol} \cdot \mathrm{L}^{-1} \mathrm{NaOH}$ at $R(\mathrm{O} / \mathrm{A})=1: 1$, while it was $88.69 \%$ in Figure 4 (b) using $1.5 \mathrm{~mol} \cdot \mathrm{L}^{-1} \mathrm{NaOH}$ at $R(\mathrm{O} / \mathrm{A})=2: 1$. It is noted that high concentration of $\mathrm{NaOH}$ will probably lead to seriously emulsification of the organic phase; thus, we should decrease the concentration of $\mathrm{NaOH}$ as far as possible on condition that the recovery is satisfactory.

3.3. Recovery of Boron after Back-Extraction. When the aqueous phase obtained during back-extraction was directly evaporated, we found that only a small quantity of 


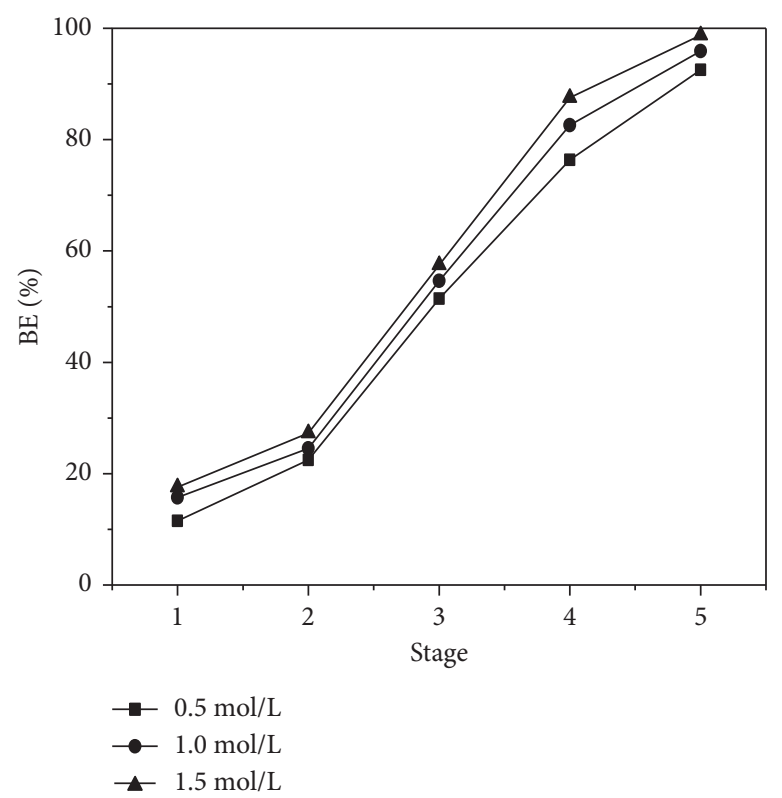

(a)

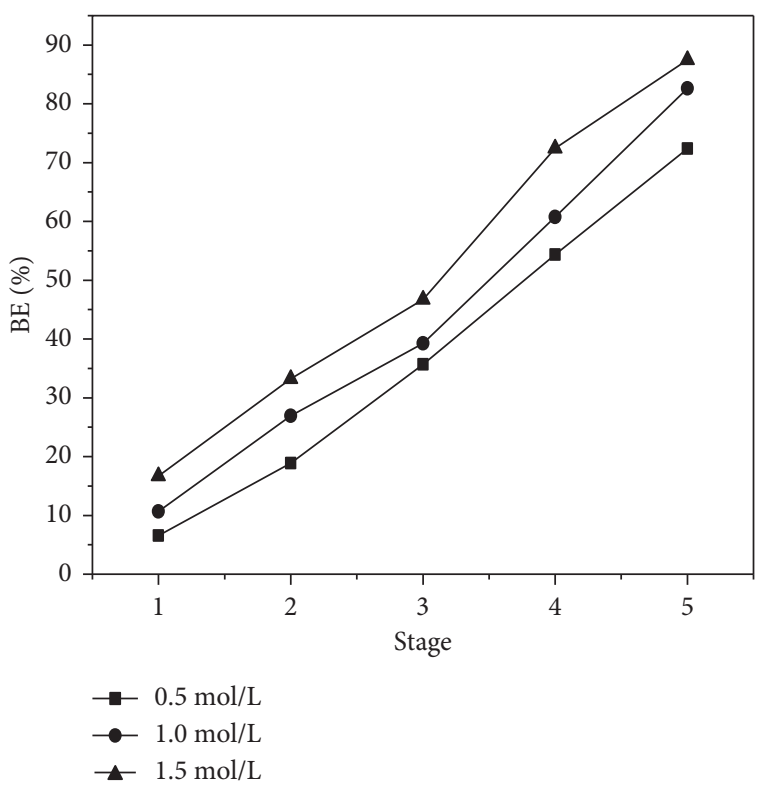

(b)

FIgURE 4: Back-extraction of boron by five-stage centrifugal extraction with $\mathrm{NaOH}$ solution at $\mathrm{R}(\mathrm{O} / \mathrm{A})=1: 1$ (a) and $2: 1$ (b)

the solid phase was obtained, and the recovery of boron was no more than $35 \%$. It is noted that $\mathrm{NaOH}$ will react with $\mathrm{H}_{3} \mathrm{BO}_{3}$ in solution to generate low solubility of sodium tetraborate $\left(\mathrm{Na}_{2} \mathrm{~B}_{4} \mathrm{O}_{7}\right)(2)$, while it will produce high solubility of sodium metaborate $\left(\mathrm{NaBO}_{2}\right.$; Table 3$)$ when the molar ratio between $\mathrm{NaOH}$ and $\mathrm{H}_{3} \mathrm{BO}_{3}$ is larger than $1: 2$ (3). Due to the molar ratio between $\mathrm{Na}$ and $\mathrm{B}$ is far higher than $1: 2$ during the back-extraction, it is certain that there was a great deal of $\mathrm{NaBO}_{2}$ existed in the aqueous phase after back-extraction:

$$
\begin{gathered}
4 \mathrm{H}_{3} \mathrm{BO}_{3}+2 \mathrm{NaOH}=\mathrm{Na}_{2} \mathrm{~B}_{4} \mathrm{O}_{7}+7 \mathrm{H}_{2} \mathrm{O} . \\
\mathrm{H}_{3} \mathrm{BO}_{3}+\mathrm{NaOH}=\mathrm{NaBO}_{2}+2 \mathrm{H}_{2} \mathrm{O} .
\end{gathered}
$$

For the reasons mentioned above, the low recovery rate of boron by evaporating directly is reasonable. We found that the solid phase was identified as tetraborate pentahydrate $\left(\mathrm{Na}_{2} \mathrm{~B}_{4} \mathrm{O}_{7} \cdot 5 \mathrm{H}_{2} \mathrm{O}\right.$; Figure $\left.5(\mathrm{a})\right)$ rather than the usually expected borax $\left(\mathrm{Na}_{2} \mathrm{~B}_{4} \mathrm{O}_{7} \cdot 10 \mathrm{H}_{2} \mathrm{O}\right)$. This situation is speculated to be the effects of $\mathrm{NaBO}_{2}$ and the excessive $\mathrm{NaOH}$ in the aqueous phase.

In order to obtain a high recovery of boron, based on the solubility data of different boron compounds in Table 3 , the aqueous phase can be acidized to $\mathrm{pH}<2.5$ and then evaporated to obtain the $\mathrm{H}_{3} \mathrm{BO}_{3}$ product. The results showed that pure $\mathrm{H}_{3} \mathrm{BO}_{3}$ was acquired (Figure 5(b)), and the recovery rate of boron was no less than $88.32 \%$.

3.4. Extraction Mechanism of Boron by EHD. The organic phase containing 30\% EHD and 70\% SK was identified by Fourier-transform infrared spectroscopy (FT-IR) before and after the extraction of boron at $\mathrm{pH}=2.0$ and $R(\mathrm{O} / \mathrm{A})=1: 2$, and the results are shown in Figure 6.
TABLE 3: Solubility of different boron compounds [20].

\begin{tabular}{lcccc}
\hline \multirow{2}{*}{ Temperature $\left({ }^{\circ} \mathrm{C}\right)$} & \multicolumn{5}{c}{ Solubility (g.100 g water) } \\
& $\mathrm{H}_{3} \mathrm{BO}_{3}$ & $\mathrm{Na}_{2} \mathrm{~B}_{4} \mathrm{O}_{7} \cdot 10 \mathrm{H}_{2} \mathrm{O}$ & $\mathrm{Na}_{2} \mathrm{~B}_{4} \mathrm{O}_{7}$ & $\mathrm{NaBO}_{2}$ \\
\hline 10 & 3.65 & 1.6 & - & 20.8 \\
20 & 4.87 & 2.5 & - & 25.4 \\
25 & 5.74 & 3.2 & - & 28.2 \\
30 & 6.77 & 3.9 & - & 31.4 \\
40 & 8.90 & 6.4 & 8.8 & 40.4 \\
50 & 11.39 & 10.5 & - & - \\
60 & 14.89 & 17.4 & - & 63.9 \\
\hline${ }^{a}$ No data. & \multicolumn{5}{c}{}
\end{tabular}

Based on the comparison of FT-IR spectrograms in Figure 6, we found that there appears new absorption peaks at $663 \mathrm{~cm}^{-1}, 1271 \mathrm{~cm}^{-1}, 1336 \mathrm{~cm}^{-1}$, and $1419 \mathrm{~cm}^{-1}$ after boron extraction. Wherein, the $663 \mathrm{~cm}^{-1}$ is the deformed vibration peak of $\mathrm{BO}_{3}$ and the $1271 \mathrm{~cm}^{-1}$ is the deformation vibration peak of $\mathrm{B}-\mathrm{O}-\mathrm{H}$, while the $1336 \mathrm{~cm}^{-1}$ and $1419 \mathrm{~cm}^{-1}$ are the stretching vibration peaks of $\mathrm{B}-\mathrm{O}$ bonds in borate ester. No B-O characteristic absorption peak of boric acid was present in Figure 6(b), indicating boron in the organic phase does not exist in the boric acid form. Therefore, it is certain that the extraction of boron by EHD mainly results from the esterification reaction between EHD and $\mathrm{H}_{3} \mathrm{BO}_{3}$ rather than the physical extraction.

In order to further reveal the extraction process and mechanism, it was investigated by the slope method. SK only acts as a diluent during the extraction of boron; thus, the reaction between $\mathrm{H}_{3} \mathrm{BO}_{3}$ and $\mathrm{EHD}$ is expressed in the following: 


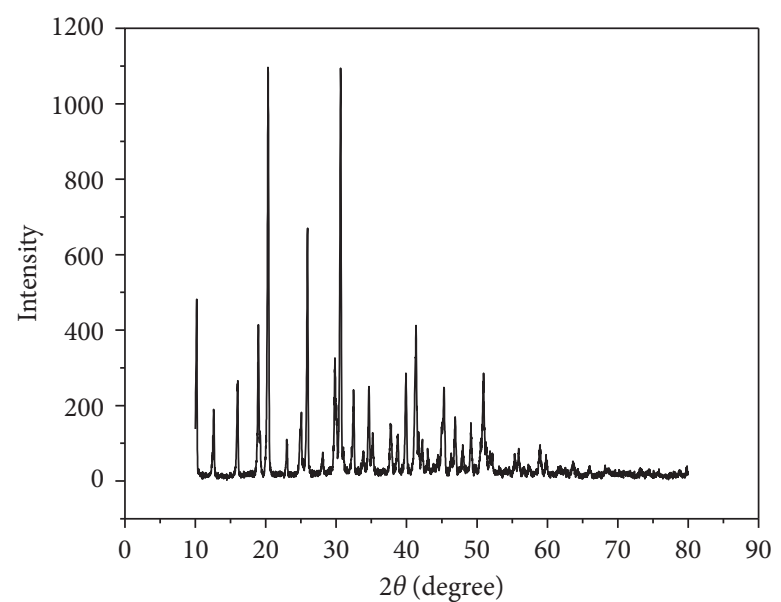

(a)

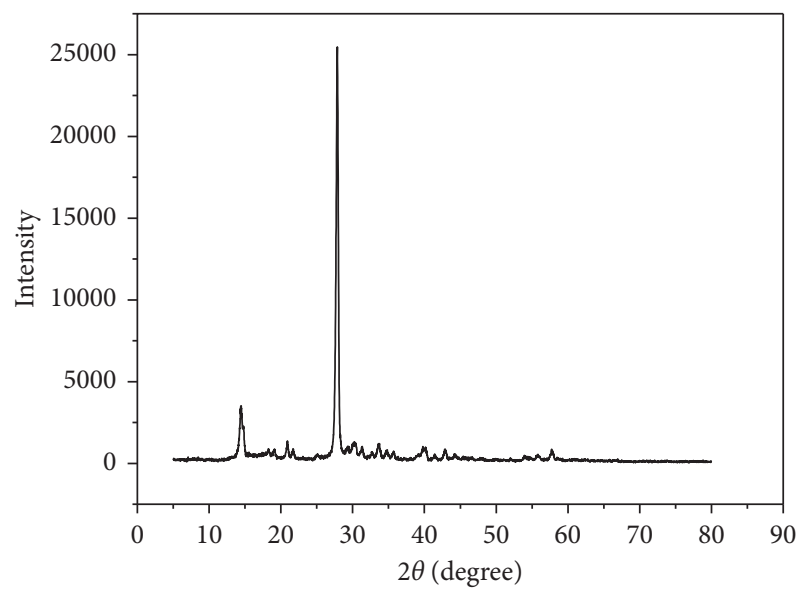

(b)

FIGURE 5: X-ray diffractograms of the solid phases generated during the evaporation of aqueous phase after back-extraction of boron. (a) Direct evaporating and (b) evaporating after acidification.

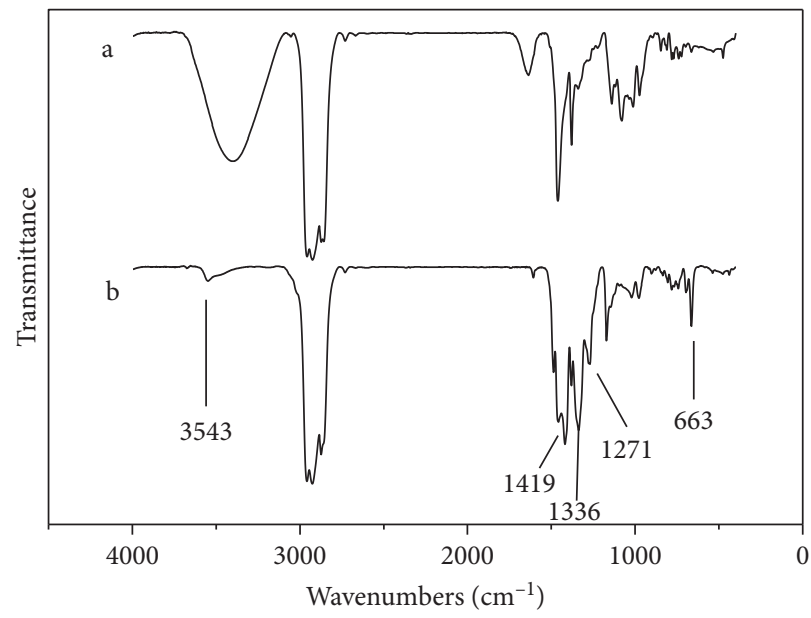

FIGURE 6: FT-IR spectrograms of organic phases before (a) and after (b) the extraction of boron.

$\mathrm{H}_{3} \mathrm{BO}_{3}$ (aqueous phase) $+m \mathrm{R}(\mathrm{OH})_{2}$ (organic phase) $\longrightarrow$

$\mathrm{H}_{3} \mathrm{BO}_{3} \cdot m \mathrm{R}(\mathrm{OH})_{2}$ (organic phase),

where $\mathrm{R}(\mathrm{OH})_{2}$ denotes the EHD and $m$ is the stoichiometric number. The apparent extraction equilibrium constant $K$ in (4) can be assumed as

$$
K=\frac{\left[\mathrm{H}_{3} \mathrm{BO}_{3} \cdot m \mathrm{R}(\mathrm{OH})_{2}\right]_{\mathrm{O}}}{\left[\mathrm{H}_{3} \mathrm{BO}_{3}\right]_{\mathrm{A}} \cdot\left[\mathrm{R}(\mathrm{OH})_{2}\right]_{\mathrm{O}} \mathrm{m}}
$$

where $\mathrm{H}_{3} \mathrm{BO}_{3}$ is a weak acid and it will hydrolyze in water according to the following hydrolysis reaction [4]:

$$
\mathrm{H}_{3} \mathrm{BO}_{3}+\mathrm{H}_{2} \mathrm{O} \stackrel{\text { reversible }}{\longleftrightarrow} \mathrm{B}(\mathrm{OH})_{4}^{-}+\mathrm{H}^{+} \quad \mathrm{pKa}=9.23 .
$$

Therefore, the extraction equilibrium distribution coefficient $D$ can be expressed as

$$
\mathrm{D}=\frac{\left[\mathrm{H}_{3} \mathrm{BO}_{3} \cdot \mathrm{mR}(\mathrm{OH})_{2}\right]_{\mathrm{O}}}{\left[\mathrm{H}_{3} \mathrm{BO}_{3}\right]_{A}+\left[\mathrm{B}(\mathrm{OH})_{4}{ }^{-}\right]_{\mathrm{A}}}=\frac{\left[\mathrm{H}_{3} \mathrm{BO}_{3} \cdot \mathrm{mR}(\mathrm{OH})_{2}\right]_{\mathrm{O}}}{\left[\mathrm{H}_{3} \mathrm{BO}_{3}\right]_{\mathrm{A}} \times\left(1+10^{\mathrm{pH}-\mathrm{pKa}}\right)}
$$

Based on Equations (5) and (7), the distribution coefficient $D$ can be reformulated into Equation (8) or further simplified into Equation (9) by considering the logarithm:

$$
\begin{gathered}
D=\frac{K \times\left[R(\mathrm{OH})_{2}\right]_{\mathrm{O}}^{\mathrm{m}}}{\left(1+10^{(\mathrm{pH}-\mathrm{pKa})}\right)} \\
\lg \mathrm{D}=m \times \lg \left[\mathrm{R}(\mathrm{OH})_{2}\right]_{\mathrm{O}}+\text { constant. }
\end{gathered}
$$

Equation (9) shows that there presents a linear relation between $\lg D$ and $\lg \left[\mathrm{R}(\mathrm{OH})_{2}\right]_{\mathrm{O}}$ at certain conditions, and the slope is the stoichiometric number $m$ in Reaction (4). During the batch experiment of boron extraction, the molar concentration of boron in brine was kept constant, while the content of EHD in the organic phase was gradually changed. 


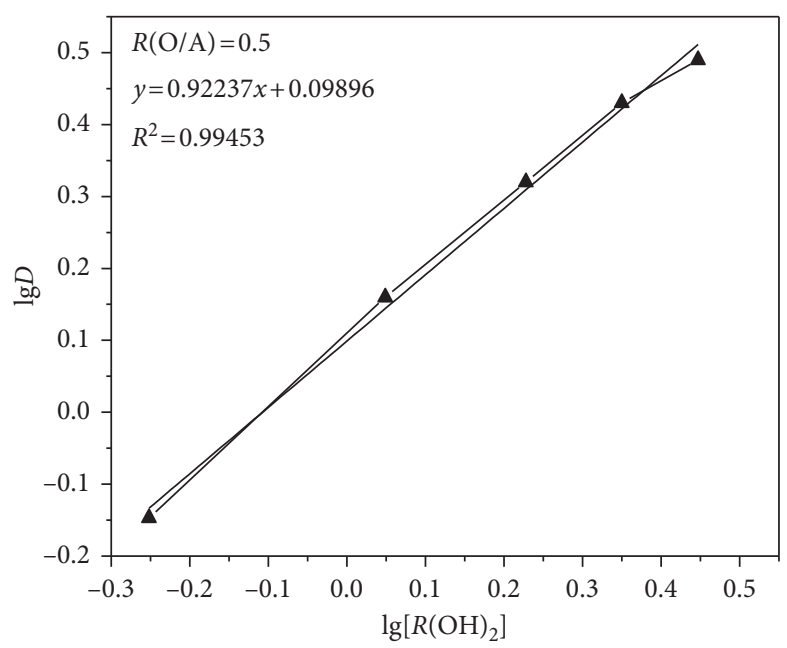

(a)

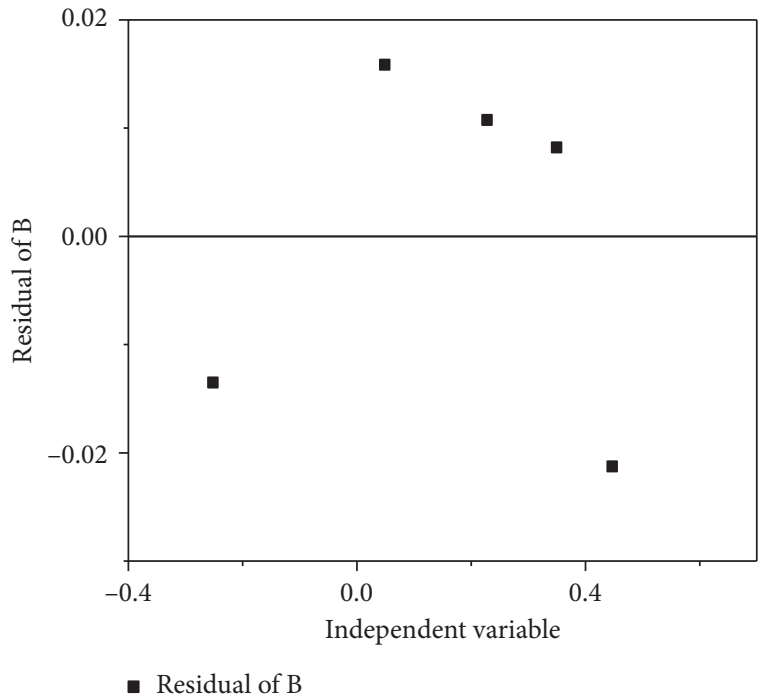

(b)

FIGURE 7: Linear relation between distribution coefficient and EHD concentration (a) and its residual analysis (b).

When the $\lg D$ and $\lg \left[\mathrm{R}(\mathrm{OH})_{2}\right]_{\mathrm{O}}$ was linear fitted, the results are shown in Figure 7.

Based on the result in Figure 7(a), we found that the linear equation is expressed as $y=0.92237 x+0.09896$, and the correlation coefficient $(r)$ reaches to 0.9973 , suggesting a good linear correlation between $\lg D$ and $\lg \left[R(\mathrm{OH})_{2}\right]_{\mathrm{O}}$. The slope is approximated to 1.0 with a standard error of $3.4 \%$; thus, the extraction of boron by EHD is mainly based on the reaction between $\mathrm{H}_{3} \mathrm{BO}_{3}$ and $\mathrm{EHD}$ at stoichiometric ratio $1: 1 . \mathrm{H}_{3} \mathrm{BO}_{3}$ can also be expressed as $\mathrm{B}(\mathrm{OH})_{3}$, and the esterification reaction between alcoholic hydroxyl and - $\mathrm{OH}$ in $\mathrm{B}(\mathrm{OH})_{3}$ will generate a stable six-membered ring structure of boric acid ester after producing two molecules of water; thus, the accurate reaction of R3 is expressed in the following reaction:<smiles>[R]C(O)CCO</smiles><smiles>[R]C1CCOB(O)O1</smiles>

\section{Conclusions}

The recovery of boron in underground brine was carried out in this work by using continuous centrifugal extraction with 2-ethyl-1,3-hexanediol, and the extraction process and mechanism were also investigated by the combination of FTIR with the slope method. The results showed that boron can be effectively extracted and separated from underground water by five-stage centrifugal extraction using 30\% EHD $+70 \% \mathrm{SK}$ at $\mathrm{pH}=2.0-3.0, R(\mathrm{O} / \mathrm{A})=1: 2$. The extraction rate for a real brine containing $17.48 \mathrm{~g} \cdot \mathrm{L}^{-1} \mathrm{~B}_{2} \mathrm{O}_{3}$ was $98.46 \%$ at the aforementioned conditions. Boron in the organic phase can be well five-stage back-extracted by $1.0 \mathrm{~mol} \cdot \mathrm{L}^{-1} \mathrm{NaOH}$ at $R(\mathrm{O} / \mathrm{A})=1: 1$ with a back-extraction rate of $97.00 \%$. Only a small quantity of tetraborate pentahydrate was obtained by the direct evaporation of the aqueous phase obtained by back-extraction, while about $88.32 \%$ boron can be recycled in the $\mathrm{H}_{3} \mathrm{BO}_{3}$ form by evaporation after acidized to $\mathrm{pH}<2.5$. The extraction mechanism revealed that the extraction of boron was completed mainly based on the esterification reaction between alcoholic hydroxyl in EHD and $-\mathrm{OH}$ in $\mathrm{B}(\mathrm{OH})_{3}$ at stoichiometric ratio $1: 1$ to generate a stable six-membered ring structure of boric acid ester after producing two molecules of water.

\section{Data Availability}

The data used to support the findings of this study are available from the corresponding author upon request.

\section{Conflicts of Interest}

The authors declare that they have no conflicts of interest. 


\section{Acknowledgments}

This study was funded by the National Natural Science Foundation of China (grant numbers U1607129, U1607123, and 21773170), the Foundation of Tianjin Engineering Center of Marine Chemical Engineering \& Technology (grant number hyhg201701), and the Yangtze Scholars and Innovative Research Team of the Chinese University (grant number IRT_17R81).

\section{References}

[1] R. B. Kistler and C. Helvaci, "Boron and Borates," Industrial Minerals and Rocks, Elsevier, New York, NY, USA, 1994.

[2] H. Z. Wei, S. Y. Jiang, and H. B. Tan, "Boron isotope geochemistry of salt sediments from the Dongtai salt lake in Qaidam basin: Boron budget and sources," Chemical Geology, vol. 380, pp. 74-83, 2014.

[3] J. C. Zhang and M. Wang, "Research on boron extraction method from salt lake brine," Chemical Minerals and Processing, vol. 5, pp. 5-7, 2005.

[4] R. Zhang, Y. M. Xie, J. F. Song et al., "Extraction of boron from salt lake brine using 2-ethylhexanol," Hydrometallurgy, vol. 160, pp. 129-136, 2016.

[5] H. Demey, T. Vincent, M. Ruiz, M. Nogueras, A. M. Sastre, and E. Guibal, "Boron recovery from seawater with a new lowcost adsorbent material," Chemical Engineering Journal, vol. 254, pp. 463-471, 2014.

[6] J. Y. Lin, Y. J. Shi, P. Y. Chen, and Y. H. Huang, "Precipitation recovery of boron from aqueous solution by chemical oxoprecipitation at room temperature," Applied Energy, vol. 164, pp. 1052-1058, 2015.

[7] E. Huertas, M. Herzberg, G. Oron, and M. Elimelech, "Influence of biofouling on boron removal by nanofiltration and reverse osmosis membranes," Journal of Membrane Science, vol. 318, no. 1-2, pp. 264-270, 2008.

[8] R. R. Grinstead, "Removal of boron and calcium from magnesium chloride brines by solvent extraction," Industrial and Engineering Chemistry Product Research and Development, vol. 11, no. 4, pp. 454-460, 1972.

[9] F. Q. Li, M. Wang, and Zh. J. Peng, "A method for separating boron from boron-containing brines," CN 103482643 B, 2015.

[10] J. Hejda and V. Jedináková, "Separation of boric acid from radioactive wastes by liquid-liquid extraction," Journal of Radioanalytical Chemistry, vol. 80, no. 1-2, pp. 23-29, 1983.

[11] J. Hejda and V. Jedináková, "Physical and chemical aspects of extraction separation of boric acid from the products of nuclear fission," Journal of Radioanalytical and Nuclear Chemistry Articles, vol. 121, no. 2, pp. 441-446, 1988.

[12] M. Karakaplan, S. Tural, B. Tural, Y. Turgut, and H. Hoşgören, "The solvent extraction of boron with synthesized aliphatic 1,3-Diols: stripping and extraction behavior of boron by 2,2,5trimethyl-1,3-hexanediol," Solvent Extraction and Ion Exchange, vol. 22, no. 6, pp. 897-911, 2004.

[13] T. O. Kwon, M. Hirata, and E. Torisaka, "Boron removal and recovery from wastewater by solvent extraction with 2-butyl2-ethyl-1,3-propanediol," in Proceedings of Asian Pacific Confederation of Chemical Engineering Congress Program and the Society of Chemical Engineers, Kitakyushu, Japan, 2005.

[14] B. Grinbaum, L. Kogan, and E. Barnea, "Process for the production of calcium bromide by liquid-liquid extraction," US, US 7452520 B2, 2008.
[15] D. M. San Lorenzo, G. D. Nogueira, and M. F. Tapia, "Mixing and settling method and device in solvent extraction processes to recover high-purity products," US, US7507343, 2009.

[16] Ch. H. Gao, X. C. Deng, and K. Zhang, "Research on extracting boron from brine by centrifugal extraction method," International Journal of Salt Lake Research, vol. 18, pp. 26-31, 2010.

[17] L. Guo, Extraction of Boron Using Centrifugal Extraction Technique from Underground Brine, Chengdu University of Technology, Chengdu, China, 2016.

[18] Qinghai Institute of Salt Lakes, Analysis of Brine and Salt, Science Press, Beijing, China, 1973, in Chinese.

[19] Qinghai Institute of Salt Lakes, Chinese Academy of Sciences; Analytical Methods of Brines and Salts, Science Press, Beijing, China, 2nd edition, 1988.

[20] Tianjin chemical research institute, Manual of Inorganic Salt Industry, Chem. Ind. press, Beijing, China, 2nd edition, 1996. 

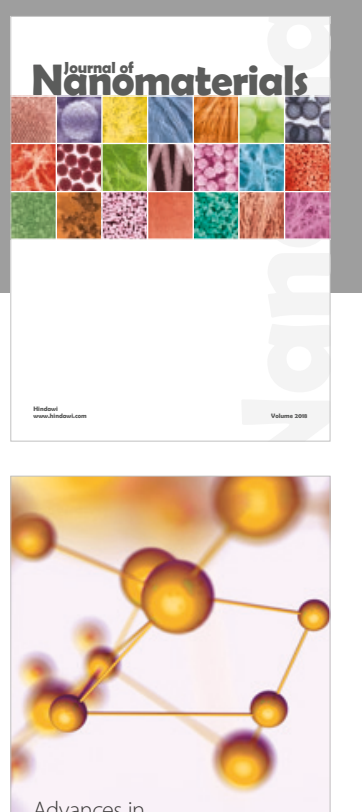

Physical Chemistry
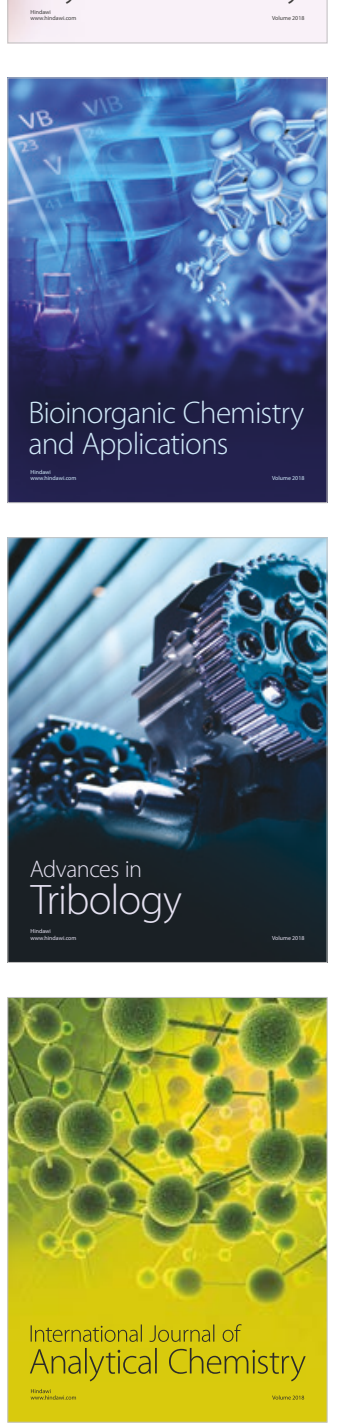

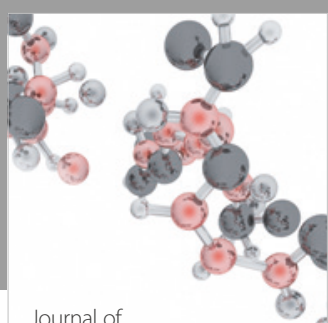

Analytical Methods

in Chemistry

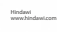

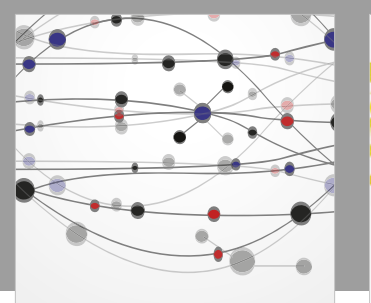

The Scientific World Journal

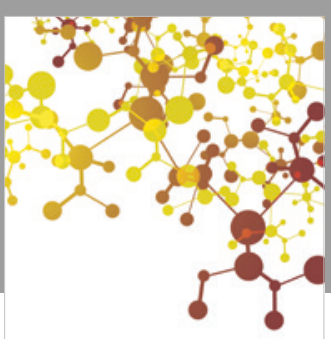

Journal of

Applied Chemistry
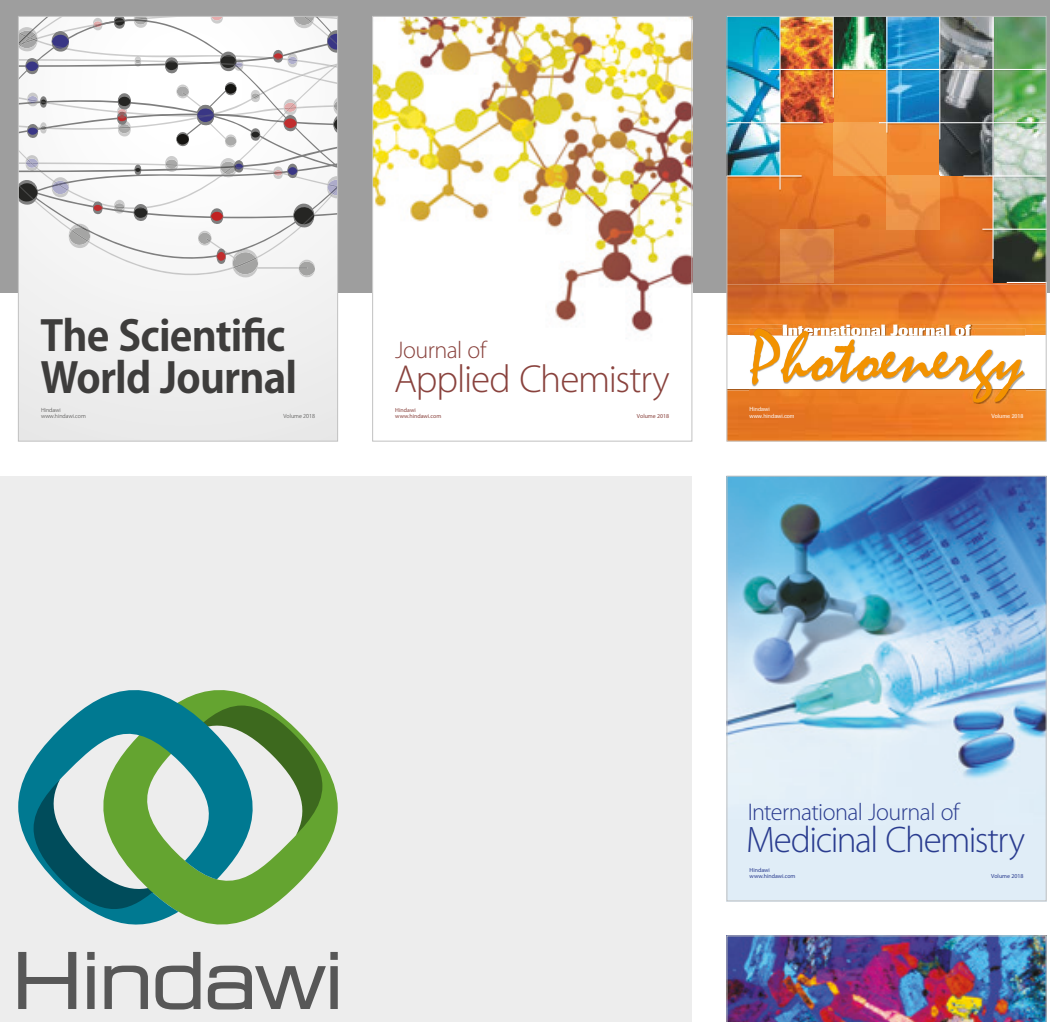

Submit your manuscripts at

www.hindawi.com
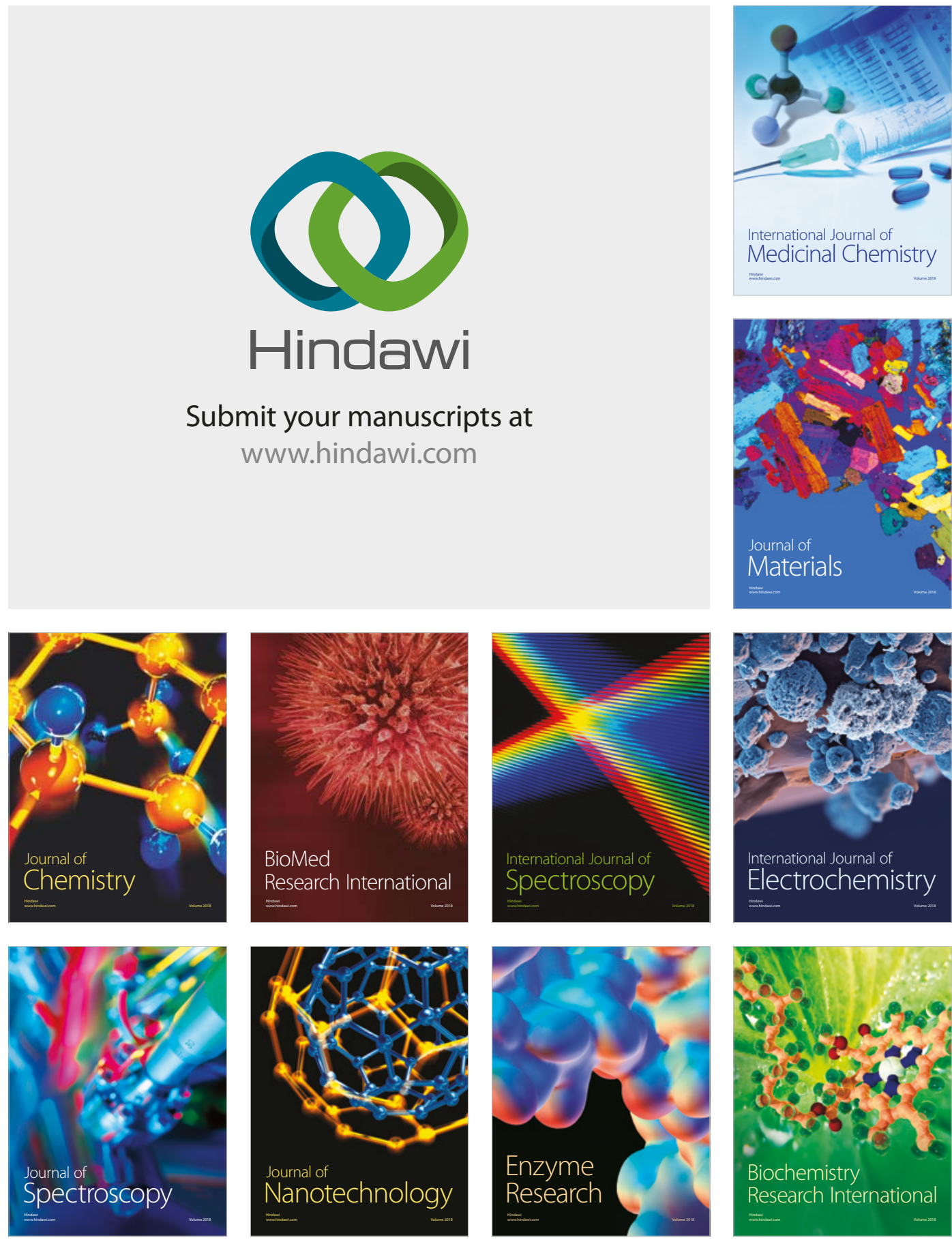
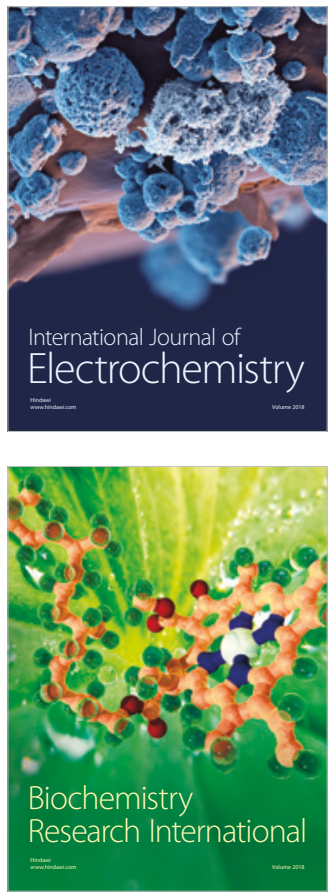